\title{
Strategies for building a complete and efficient online shopping supply chain system
}

\author{
Hui $\mathrm{He}^{1, \mathrm{a}}$,GuoXiong $\mathrm{Li}^{2}$, b \\ ${ }^{1}$ Electronic Commerce Department of Business School JiangXi Normal University NanChang, China \\ ${ }^{2}$ Electronic Commerce Department of Business School JiangXi Normal University NanChang, China
}

\begin{abstract}
In the electricity business enterprise different sales model, the different consumer online shopping behavior will result in different market demand, the different market demand for the influence of e-commerce supply chain system is different also, therefore, it is necessary for e-commerce enterprises to determine the network equilibrium conditions of the whole e-commerce supply chain according to the online shopping behaviors of consumers in different market demands under different sales modes, so as to improve the operational efficiency of e-commerce supply chain. Through the analysis of supply chain network, online shopping, consumer behavior and its influencing factors in four levels of supplier, e-retail, express business and market demand, this paper reviews and summarizes the supply chain network equilibrium model and its application research status, and analyzes the equilibrium problem of online supply chain system under different conditions from the perspective of consumer online shopping behavior research. Relevant strategies are proposed.
\end{abstract}

\section{INTRODUCTION}

Since 2008, the development of e-commerce has entered a new era, the online shopping market has maintained a rapid development momentum, and the transaction scale has continued to expand at a high speed. The exponential growth in e-commerce sales has highlighted the huge potential of the online retail market. Products sold by ecommerce cannot be separated from production, transportation and distribution. The rapid development of e-commerce has driven the rapid development of manufacturing and logistics enterprises, and e-commerce has become a driving force for the rapid and sustainable growth of the national economy. The rapid development of e-commerce has brought excessive profits to merchants and affordable products to consumers, but the resulting supply chain problems should not be underestimated ${ }^{[1-2]}$.

Different from the traditional supply chain system driven by seller, online shopping supply chain is driven by buyer ${ }^{[3]}$. In this system, consumers place orders to ecommerce enterprises, while e-commerce enterprises place orders to manufacturing enterprises, arrange transportation for logistics enterprises, and deliver products to consumers through logistics. Consumers make feedbacks according to product conditions so as to complete the transaction process. In this process, consumers are the originator and terminator of transactions, and consumer satisfaction determines whether a transaction can be completed smoothly ${ }^{[4]}$. In addition to the quality of the product itself, electricity and logistics enterprise service quality also affects the consumer satisfaction, and the influence degree is higher, but the present stage of online consumer satisfaction generally is not high. Different consumer online shopping behavior will lead to different orders, the influence of different orders of e-commerce supply chain system is different also, the study of consumer online shopping behavior, to determine the factors influencing consumer online shopping behavior, according to consumer demand to determine supply decisions can effectively solve the above problems. According to the online consumer shopping behavior research with supply chain system equilibrium conditions, online shopping the supply policy makers provide theoretical basis for the rational decisionmaking and reference which in order to achieve manufacturing industry to reduce inventory and stable development of electricity industry. The logistics industry service diversification and increasing consumers' online shopping satisfaction of the benign development of the ecommerce supply chain system will be achieved finally ${ }^{[5-}$ 6].

\section{METHODOLOGY AND DISCUSSION}

For enterprises, how to build a complete and efficient supply chain system? This is a huge and complex question, and no one can answer it in a few words. Moreover, different types of enterprises vary greatly, if only one standard to measure or use a template to apply, often will be biased. Therefore, we may put forward this question from another Angle, namely: what characteristics does a complete and efficient enterprise supply chain system usually have? 


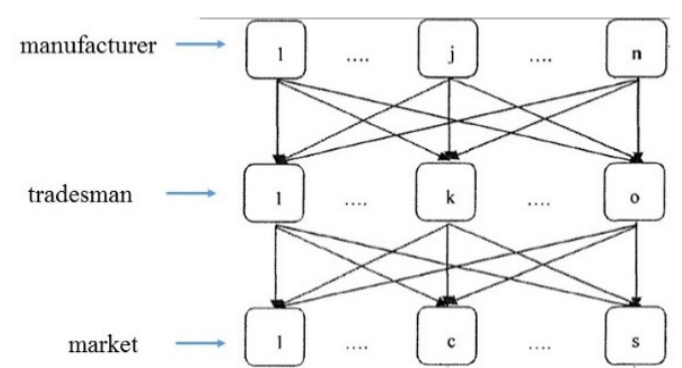

Fig 1. The network structure of supply chain

According to the structure of the supply chain in Figure 1, a complete and efficient online shopping supply chain system strategy is proposed. These characteristics can also be called commonality. No matter what country they come from or what industry they come from, what these successful supply chain enterprises have done in building a complete and efficient supply chain system can be summarized as follows:

1. Clear supply chain strategies and strategies driven by customer value

Enterprises need to create value for multiple parties, such as customers, employees, shareholders, and even the community or society. However, all of these should be traced back to the creation of value for customers, which is the basis of enterprise survival and the initial heart of supply chain management.

However, although many enterprises write "customer value" into the enterprise strategy, they ignore its core position in the supply chain strategy. It is easy to see that in many real cases, "cost" is the highest strategy in the supply chain, and it is probably not clearly related to the "customer value" we are looking for ${ }^{[7]}$.

2. A sound supply chain management organizational structure system and a complete talent construction mechanism

There is no single answer as to how the supply chain should be structured. It is impossible for enterprises in different industries and of different sizes to be stereotyped. However, one thing is clear: the supply chain should be organized in an integrated manner.

Talent is the foundation of everything! Only the organization has no talent, no matter how good the organizational structure is useless! Similarly, excellent supply chain management talents are always scarce in the talent market. The reason is very simple, the development of supply chain management in China is short, very few successful enterprises. However, supply chain management is a comprehensive discipline with strong practicality. It usually takes at least ten years to train a professional talent. It is conceivable that the time is long and the difficulty is great. Therefore, the enterprise should establish a complete talent introduction and training mechanism, to have a ten-year determination, long-term adhere to the supply chain recruitment, recruitment and retention $^{[8]}$.

3. Perfect supply chain coordination process and mechanism across departments and enterprises

Supply chain management is cross-departmental and cross-enterprise, but supply chain departments have their boundaries. No matter how big a company's supply chain is, it is impossible to include everyone. Even if it is included, it is impossible to solve all the problems. On the contrary, it will lead to overstaffed organizations and unclear division of labor. For example, does the sales end connect the customer as part of the supply chain? Of course! But we cannot integrate the sales department into the supply chain management department ${ }^{[9]}$.

Therefore, an efficient supply chain organization should focus on the process, coordinate all departments within the enterprise and all partners outside the enterprise, so that everyone can work towards the same goal and direction. These processes include: product development collaborative process, sales and operations collaborative process, planning collaborative process, procurement collaborative process, sales collaborative process.

4. Complete product and service lifecycle management

The right products and services are what the supply chain ultimately delivers to customers! Centering on customer needs, designing products, selecting goods and customizing services are closely related to the supply chain. Unfortunately, many enterprises strictly separate the work related to products, goods and services from the supply chain, and there are few intersections and connections between each other, let alone the supply chain process structured according to the life cycle of products and services.

Therefore, we often see examples like this: a hood with many different sizes of screws; An unsalable commodity sits quietly in a warehouse for a year until its expiration date. The modification of a product specification is not notified to the supplier; A product that is still under warranty can not buy repair parts...Many similar examples can be attributed to the absence of lifecycle management processes for products or services.

Products have their own life cycle, just as people have their own life cycle. At different stages of the life cycle, the supply chain strategy must be adjusted. For example, in the stage of product research and development, suppliers or customers can be invited to intervene in the early stage to help the research and development department to clearly locate the problem points of product demand and supply; In the product launch stage, the planning department needs to prepare the right amount of materials.

5. A sound supply chain management index assessment system

The evaluation index design of supply chain management is very complex! On the surface, the KPI of the supply chain seems to be only cost, delivery, quality and service, but if these indicators are broken down in detail, dozens or hundreds of indicators will be found. Not to mention the fact that they often contradict and restrict each other, different companies and different business modules can be quite different in terms of the definition of indicators.

The index of a sound supply chain must be able to support the competitive strategy of an enterprise. For example, if an enterprise chooses a cost-leading strategy, cost is the most core index. One of the KPI, such as delivery and quality, is the most core indicator for enterprises that choose a differentiated competitive strategy. The advantage of choosing a metric as the core metric is that it makes business management more focused. But this does not mean abandoning other indicators on 
which companies still need to keep up with the industry average. It is impossible for an enterprise to achieve the best of all supply chain indicators, so the setting of supply chain indicators tests the wisdom of the highest level of the enterprise.

6. A corporate culture that supports supply chain innovation and promotes continuous improvement

Supply chain development depends not only on strategic strategy, organizational structure, talent and process, but also on the culture of the enterprise. The vitality of an enterprise's supply chain also depends on whether it has established an enterprise culture that encourages innovation and continuous improvement in the supply chain. Innovation and continuous improvement is not just a process. If innovation and continuous improvement are managed only as a process, then innovation will die!

7. Perfect supply chain risk control process

In the operation of the supply chain, there are numerous risks and various uncertainties. If an enterprise is not careful, it will fall into a deep pit and never be saved. For example, tianjin Port explosion, a large number of cars were destroyed in an instant; Another example is the trade war between China and the United States. The list goes on and on!

In the process of enterprise development, it is necessary to build a firewall to guard against risks. To deal with risks, companies need to first understand where they are coming from. Some of them come from inside, which is called endogenous risk, such as information distortion and moral risk. Some are external, such as political risk, exchange rate risk, legal risk and so on. On this basis, the enterprise should establish the relevant risk control process around each risk type, and control the risk at the lowest level through the pre-event, in-event and postevent control.

\section{CONCLUSION}

The traditional supply-demand matching mode, traditional purchasing and selling mode, forecasting model and planning process advocated by the traditional supply chain are more and more difficult to keep pace in the era of fragmented, real-time and diversified demand. Nowadays, the supply chain system of the whole society is undergoing great and rapid changes. For example, driven by the new retail, the perception of demand has been extended from stores to communities, the user portrait has been extended from offline to online, the logistics network has been extended from the central city to the countryside, and the planning mode has been extended from a single enterprise to the network. Only by quickly adapting to the changes, constructing the resultant model of supply and demand balance, and establishing a complete and efficient supply chain system, can we finally realize the lean supply chain with "high revenue, high turnover and high return"!

\section{ACKNOWLEDGMENT}

This research was supported by the Education Department Science Foundation of Jiangxi Province (No. GJJ150370)

\section{REFERENCES}

1. Nagurney A, Dong J, Zhang D. A supply chain network equilibrium model $[\mathrm{J}]$. Transportation Research Part E, 2002, (38) : 281-303.

2. Nagurney A, Jon Loo, Dong J, Zhang D. Supply chain networks and electronic commerce: a theoretical perspective $[\mathrm{J}]$. Netnomics, 2002, (4) : 187-220.

3. A general multitiered supply chain network model of quality competition with suppliers[J] . Dong Li,Anna Nagurney. International Journal of Production Economics . 2015

4. Ambad, P. M. \& Kulkarni, M. S. (2015). An attractiveness index based approach for warranty optimization. International Journal of Quality \& Reliability Management, 32(4): 415-431.

5. $\mathrm{Wu}, \mathrm{S}$. (2014). Warranty return policies for products with unknown claim causes and their optimisation. International Journal of Production Economics, 156: 52-61.

6. Huysentruyt, M. \& Read, D. (2010). How do people value extended warranties? Evidence from two field surveys. Journal of Risk and Uncertainty, 40(3): 197-218.

7. Q.. Qiang, K. Ke, T. Anderson, J. Dong.The closedloop supply chain network with competition distribution channel investment and uncertainties Omega, 41 (2013), pp. 186-194

8. Exploring the Relationships Between e-shopping Attitudes and Urban Freight Transport[J] . Antonio Comi,Agostino Nuzzolo. Transportation Research Procedia . 2016

9. A multi-population algorithm to solve the VRP with stochastic service and travel times[J] . Andres Gutierrez,Laurence Dieulle,Nacima Labadie,Nubia Velasco. Computers \& Industrial Engineering . 2018 